\title{
Etio-Morphological Spectrum of Bone Marrow in Pancytopenia
}

\author{
Indira Priyadarshini Anubrolu, Rashmi K Patil* and Shreekanth K Kittur
}

Department of Pathology, Belagavi Institute of Medical Sciences, Belagavi District, Karnataka, India.

\begin{abstract}
Background: Pancytopenia is a descriptive term referring to reduction in all three blood cell lineages: erythrocytes, leukocytes and platelets. A spectrum of primary and secondary disorders affecting the bone marrow may manifest with pancytopenia. The present study was carried out to know the morphological spectrum of bone marrow in pancytopenia patients and also to evaluate the causes of pancytopenia with the help of bone marrow examination.

Methods: A prospective observational study was done for a period of 18 months that included 77 pancytopenia patients diagnosed based on haemoglobin concentration, total leukocyte count and platelet count. Detailed clinical history, haematological findings, radiological findings, serological and biochemical findings were taken as and when required for all the patients. Bone marrow aspiration and/or biopsy were done in all patients to assess the morphology of bone marrow and causes of pancytopenia.

Results: The age distribution in 77 cases ranged from 18 months to 80 years. The most common affected age groupwas 31-45 years. The males were affected more commonly than females with M:F ratio of 1.7:1. The various causes of pancytopenia were megaloblastic anemia (64.9\%), HIV associated dysplasia (15.6\%), mixed nutritional deficiency anemia (5.2\%), aplastic anemia (5.2\%), acute myeloid leukemia $(2.6 \%)$, idiopathic thrombocytopenic purpura (2.6\%), myelofibrosis $(1.3 \%)$ acute lymphoblastic leukemia $(1.3 \%)$ and myelodysplastic syndrome (1.3\%). The most common bone marrow finding was erythroid hyperplasia with megaloblastic maturation.

Conclusion: Pancytopenia should be suspected on clinical grounds in patients with decreased appetite, weakness, prolonged fever and tendency to bleed. Detailed primary haematological investigations coupled with bone marrow examination were vital in establishing diagnosis in pancytopenia patients. A large proportion of pancytopenia wasattributable to megaloblastic anemia which was amenable to treatment. Hence, early and accurate diagnosis is lifesaving.
\end{abstract}

Keywords: Pancytopenia, Bone Marrow Examination, Megaloblastic Anemia

\section{Introduction}

Pancytopenia is the reduction in all the three major formed elements of blood to levels below their normal limit. It is not a disease entity but a triad of findings that result from a number of disease processes primarily or secondarily affecting the bone marrow encountered in our day-today clinical practice with high morbidity and mortality. ${ }^{[1]}$ The incidence of various disorders causing pancytopenia depends on factors like difference in age patterns, nutritional status, prevalence of infections, geographic distribution and genetic disturbances. ${ }^{[2,3]}$ A comprehensive clinical, hematological and bone marrow study forms the bedrock to evaluate the cause of pancytopenia. ${ }^{[4,5]}$ Bone marrow aspirate has been mainly utilized for cytomorphological assessment and trephine biopsy reveals marrow cellularity, focal lesions like fibrosis, granulomas or gelatinous transformation and extent of infiltration by various pathologic entities. ${ }^{[6]}$ Both the procedures are complimentary to each other and are essential in complete workup and evaluation of pancytopenia. ${ }^{[5]}$ Hence, the current study was undertaken to evaluate the etiology and study the morphology of bone marrow in pancytopenia using bone marrow examination, which would help in implementing timely and appropriate treatment to pancytopenic patients at our tertiary care teaching hospital.

\section{Materials and Methods}

The present prospective study was undertaken during the period from November 2015 to April 2017 at Hematology Unit, Department of Pathology after obtaining approval from Institutional Ethics Committee. The study included 77 patients of all age groups and both the genders fulfilling the criteria of pancytopenia on initial workup i.e., Hemoglobin concentration ( $\mathrm{Hb} \%$ ) below $10 \mathrm{~g} \%$, Total leukocyte count (WBC count) below $4 \times 10^{9} / \mathrm{L}$ and Platelet count below $100 \times 10^{9} / \mathrm{L}^{[5]}$ They were subjected to bone marrow aspiration (BMA) and/ or bone marrow biopsy (BMB) after obtaining the written consent. BMA smears were stained with Leishman's and Perl's routinely and with special stains like Periodic acid - Schiff and myeloperoxidase wherever required. Specimen obtained 
from BMB were fixed in $10 \%$ aqueous formalin solution, decalcified in $10 \%$ nitric acid solution, processed routinely and sections were stained with hematoxylin and eosin routinely and reticulin stain whenever required. All relevant clinical data, detailed physical examination findings, other serological and radiological findings were noted.

\section{Results}

The study population consisted of 77 patients with a mean age of 33.3 years and age range between 18 months to 80 years. Most of the patients were in the age group of 3145 years $(37.66 \%)$ with Male: Female(M:F) ratio of 1.7:1. In paediatric age group $(<15$ years) there were $11(14.28 \%)$ cases who presented with pancytopenia out of which 3 cases were males and 8 were females with M:F ratio of $0.4: 1$.

In adult patients presenting with pancytopenia, megaloblastic anemia (MA) (47 cases) was the most common cause. Followed by HIV-associated dysplasia ( 8 cases), mixed nutritional deficiency anemia of iron and vitamin B12/folic acid (4 cases), aplastic anemia (AA) ( 2 cases), acute myeloid leukemia (AML)( 2 cases), and idiopathic thrombocytopenic purpura(ITP), myelofibrosis and myelodysplastic syndrome (MDS)(1 case each) in adult patients. (Table 1)

HIV associated dysplasia was the most common cause of pancytopenia in children( 4 cases). MA( 3 cases $), \mathrm{AA}(2$ cases), ITP and acute lymphoblastic leukemia (ALL)(1 case each) were the other causes in paediatric patients.

The most common presenting symptoms in these patients were decreased appetite $(66.23 \%)$, generalised weakness (63.64\%) and fever (49.35\%). Other less common complaints were dyspnoea, vomiting, loose stools, giddiness, jaundice, cough, odema, weight loss, bleeding diathesis and palpitation.

On examination all patients diagnosed with pancytopenia had pallor (100\%), $40.3 \%$ of patients had icterus, splenomegaly was seen in $23.4 \%$, hepatomegaly in $12.9 \%$ and hepatosplenomegaly in $9.1 \%$ of cases.

The haemoglobin concentration was severely decreased $(<5 \mathrm{~g} / \mathrm{dL})$ in most of the cases $(40,51.9 \%)$, whereas, WBC count was moderately decreased (1001-3000 cells/cumm) in most cases $(66,85.7 \%)$ and platelet count was mildly decreased $(50,001-1,00,000 /$ cumm $)$ in most of the cases $(39,50.6 \%)$.

On peripheral smear examination, dimorphic blood picture was the most common finding seen in $71.4 \%$ of cases and most commonly seen in MA(36 cases). These findings had statistical significance with $\mathrm{p}$ value $<0.001$.
Most of the pancytopenia cases showed hypercellular marrow (85.7\%). Hypocellular marrow was seen in $5.2 \%$ and normocellular marrow in $2.6 \%$ of cases. Myeloid:Erythroid ratio was normal in 5 cases $(6.5 \%)$. Erythroid series hyperplasia was seen in most of the cases $(85.7 \%)$, myeloid cell hyperplasia was seen in 1 case (1.3\%).(Figure 1)

Erythroid hyperplasia with megaloblastic maturation was the most common bone marrow aspiration finding seen in 49 cases $(63.6 \%)$ (Figure 2), other finding was mixed maturation in 4 cases $(5.2 \%)$ in which both micronormoblasts and megaloblasts were seen. Normal erythroid maturation with normal cellularity was seen in 2 cases $(2.6 \%)$ and with decreased cellularity was noted in 6 cases (7.8\%). Iron stores were assessed using Perl's Prussian blue stain and were normal in most of the cases $(84.4 \%)$, low in 4 cases $(5.2 \%)$ and high in 1 case $(1.3 \%)$. In 50 cases $(64.9 \%)$ MA was reported, 10 cases $(13.0 \%)$ were reported as HIV-associated dysplasia, 4 cases each $(5.2 \%)$ as mixed nutritional deficiency anemia and AA, 2 cases $(2.6 \%)$ as ITP, 1 case each $(1.3 \%)$ as AML, ALL and MDS. Bone marrow aspiration was inconclusive in 5 cases $(6.5 \%)$ due to diluted marrow/dry tap and bone marrow biopsy was diagnostic in these cases. (Table 2)

Bone marrow biopsy was done in 21/77 cases and it showed MA in 15 cases (71.4\%), HIV-associated dysplasia ( 2 cases, 9.4\%) and one case (4.8\%) of AML(Figure 3), myelofibrosis(Figure 4), AA and MDS respectively. (Table 3)

In this study, $\mathrm{MA}(64.9 \%)$ was the most common cause of pancytopenia, followed by HIV-associated dysplasia(15.6\%), and mixed nutritional deficiency anemia and $\mathrm{AA}(5.2 \%$ each). Other causes of pancytopenia were AML and $\operatorname{ITP}(2.6 \%$ each), ALL, myelofibosis and $\operatorname{MDS}(1.3 \%$ each).

DISCUSSION: Pancytopenia is a common haematological problem encountered in clinical practice with variation in frequency of diagnostic entities causing pancytopenia attributable to difference in methodology and stringency of diagnostic criteria, geographic area and period of observation, genetic differences and varying exposure to myelotoxic agents. There are varying reports on underlying cause of pancytopenia from various parts of the world. In India, with diverse ethnic population, different dietary and social customs, the incidence of pancytopenia and its associated problem has not been adequately documented. ${ }^{[8]}$ The present study included 77 pancytopenia patients in whom analysis of presentation, bone marrow morphology and causes of pancytopenia were done. 
This study highlights some of the important causes of pancytopenia that may guide the treating physicians in proper management of pancytopenia patients. In the present study males were commonly affected than females with M:F ratio of 1.7:1. This finding is similar to study done by Viadya et al (1.3:1).$^{[8]}$ Study done by Hamid et al and Sale et al showed almost equal distribution of cases between males and females $(1.03: 1 \& 0.9: 1) \cdot{ }^{[9,10]}$ In paediatric age group ( $<15$ years), females were most commonly affected in present study with M:F ratio of $0.4: 1$ and study done by Dubey et al also showed female predominance in their study with M:F ratio of $0.88: 1 .^{[11]}$ This finding was different from that of the study done exclusively in children by Jan et al with M:F ratio of 1.8:1. ${ }^{[12]}$ This difference could be accounted for the large difference in the sample size in various studies. (Table 4)

In present study, the most common age group to be affected was between 31-45 years (29cases, 37.66\%) and next common age group to be affected was 16-30 years where 21 cases $(27.28 \%)$ were seen. In study done by Hamid et al, Sale et al and Nigam et the most common age group to be affected were also middle aged patients i.e., 16-30 years $(37.3 \%), 21-30$ years $(32 \%)$ and $20-40$ years $(38.7 \%)$ respectively. ${ }^{[9,10,13]}$

The common clinical presentation in present study was with the symptoms related to anemia like generalised weakness, dyspnoea and giddiness, followed by symptoms related to neutropenia and thrombocytopenia. These findings were similar to study done by Sale et al. ${ }^{[10]}$ Whereas the study done by Hamid et al and Nigam et al showed fever as the common presenting complaint. ${ }^{[9,10]}$

On physical examination, pallor was seen in all pancytopenic cases. The other common physical finding was icterus seen in $31(40.3 \%)$ cases. Splenomegaly was seen in $18(23.4 \%)$ cases and hepatomegaly was seen in 10 patients $(12.9 \%)$. In study done by Hamid et al pallor was seen in $100 \%$ cases and splenomegaly in $44 \%$ cases, which was higher in incidence compared to the present study. ${ }^{[9]}$

In present study, MA was the most common cause of pancytopenia (50cases, $64.9 \%$ ). Similar observations were made in other studies from India include Gayathri et al (74.07\%), Khunger et al (72\%), Khodke et al (44\%) and Tilak et al $(68 \%){ }^{[1,2,3,14]}$ The incidence of MA as a cause of pancytopenia varies from $0.8 \%$ to $68 \% .^{[2,3,15,16,17]} \mathrm{A}$ possible explanation for the deficiency of vitamin B12 and folic-acid in our region could be due to various chronic inflammatory disorders of the gut like chronic diarrhoeas, parasitic infections and malabsorption states, apart from poor nutrition. ${ }^{[8]} \mathrm{MA}$ is an important cause of pancytopenia occurring in critically ill patients ${ }^{[18]}$ and should be promptly notified as it is rapidly correctable disorder. ${ }^{[12]}$ Premkumar et al in his study mentioned that bone marrow examination has sensistivity of $90 \%$ in diagnosis of MA. ${ }^{[19]}$ In study done by Kumar et al and Jha et al the most common cause of pancytopenia was hypoplastic marrow $33.33 \%$ and $29 \%)$ followed by MA (23.64\%) and erythroid hyperplasia $(27.08 \%){ }^{[15,18]}$ In another study, done by Hamid et al in Yemen showed that hypersplenism $(28.0 \%)$ was the most common cause of pancytopenia. High incidence of hypersplenism was attributed to high prevalence of malaria, kalaazar and other infectious diseases in Yemen. ${ }^{[9]}$

HIV-associated dysplasia (12cases, 15.6\%) was the second commonest cause of pancytopenia in the present study which was attributable to socio-demographic profile of patients and role of high-risk practices. Pancytopenia in these patients was associated with advanced HIV-stage and presence of high viral load. ${ }^{[20]}$ The main mechanism of cytopenia in HIV infected patients is disturbed bone marrow cytokine homeostasis. ${ }^{[21]}$ Patients with HIV infection showed erythroid dysplasia with florid megaloblastic changes in most of the cases (10/12 cases) with normal myelopoiesis and megakaryopoiesis. One case presented with erythroid hyperplasia with normoblastic maturation and another case showed normal bone marrow representing refractory anemia or evolution of hypoplasia/ aplasia and requiring regular haematological follow-up. ${ }^{[7]}$ Study done by Gandhi et al and Santra et al showed that HIV infection was the cause for pancytopenia in only $3.37 \%$ and $1.8 \%$ respectively. ${ }^{[22,23]}$

In paediatric age group, HIV infection (4/11 cases) was most common cause of pancytopenia indicating the prevalence of disease in our geographical region. Next common cause of pancytopenia in children was MA (27.3\%). AA was seen in only $18.2 \%$ of cases. These findings were not in concordance with studies done by Dubey et al and Rathode et al where the most common cause of pancytopenia in children was MA $(47 \%$ \& $26.5 \%)$ followed by AA $(25.8 \%$ \& $20 \%)$ respectively. ${ }^{[11,24]}$ In other studies done in paediatric pancytopenic cases by Khan et al and Memon et al AA $(32.2 \% \& 23.9 \%)$ was the most common cause of pancytopenia followed by MA $(13 . .2 \%$ \& $13.04 \%){ }^{[25,26]}$

The third most common cause for pancytopenia in present study was mixed nutritional deficiency of iron and vitamin B12/folic-acid constituting 4 cases (5.2\%). Study done by Gupta et al and Rehmani et al showed that mixed nutritional deficiency anemia as the cause of pancytopenia in $15.98 \%$ and $12.3 \%$ of cases showing the burden of nutritional deficiency in India. ${ }^{[7,27]}$ A possible explanation for incidence of mixed nutritional anemia was attributed to extremes of age, nutritional deficiencies, malabsorption, 
parasitic infestations, and chronic gastrointestinal or genitourinary bleed. ${ }^{[27]}$

The incidence of AA quoted from western countries was $10-25 \%$ and in various places of India was between $7.7 \%$ and $43 \%{ }^{[7,28]}$ whereas in present study incidence was $5.2 \%$. Geographic difference in incidence of AA is implicated to use of causal drugs, exposure to chemicals and other external factors. In studies done by Sale et al and Premkumar et al and showed similar results of $10 \%$ and $7.9 \%$ of AA cases. ${ }^{[10,19]}$ In contrast, studies done by Vaidya et al and Kumar et al showed higher incidence of AA in their studies $(31.33 \% \& 33.33 \%){ }^{[8,15]}$

In our study, we encountered three cases of acute leukemia, two of which were $\operatorname{AML}(2.6 \%)$ and one case was ALL(1.3\%). Studies done by Sale et al $(3 \%)^{[10]}$ showed similar findings, whereas Vaidya et al $(9.64 \%)^{[8]}$ and Premkumar et al (7.9\%), ${ }^{[19]}$ showed higher incidence of acute leukemia as cause of pancytopenia.

ITP was the cause of pancytopenia in two cases $(2.6 \%)$ of present study. Study done by Sale et al and Nigam et al showed $2 \%$ and $1.93 \%$ cases of ITP as cause of pancytopenia respectively ${ }^{[10,13]}$. The bone marrow showed increase in megakaryocytes with normal maturation and occasional cells showing hypolobation and hypogranular appearance.

Myelofibrosis was seen in one case $(1.3 \%)$ where bone marrow aspiration was a dry tap, bone marrow biopsy revealed megakaryocytic hyperplasia, fibrosis and grade 2 reticulin fibres on reticulin stain. In study done by Sale et al (2\%) and Al-Awadi et al (1.3\%) showed similar results as cause of pancytopenia. ${ }^{[10,29]}$ Though myelofibrosis was not the most common cause of pancytopenia, it was an important differential diagnosis in patients with dry tap.

MDS was seen in one case $(1.3 \%)$ in present study and this finding was similar to that seen in the studies done by Kumar et al (8.33\%), Premkumar et al (0.7\%), Al-Awadi et al $(1.3 \%)$ and Pereira et al $(8.75 \%) .{ }^{[15,19,29,30]}$

Limitation of our study was unavailability of facilities for biochemical analysis of serum vitamin-B12 and folate levels and hence exact deficiency was not identified.

Table 1: Age-wise distribution in pancytopenia cases.

\begin{tabular}{|c|c|c|c|c|c|c|c|}
\hline \multirow{2}{*}{ Causes of pancytopenia } & \multicolumn{6}{|c|}{ Age in years } & \multirow{2}{*}{ Total } \\
\hline & $0-15$ & $16-30$ & $31-45$ & $46-60$ & $61-75$ & $75-90$ & \\
\hline MA & 3 & 17 & 20 & 8 & 1 & 1 & 50 \\
\hline HIV & 4 & 1 & 6 & - & 1 & - & 12 \\
\hline Mixed anemia & - & 1 & 1 & 1 & 1 & - & 4 \\
\hline AA & 2 & 1 & 1 & - & - & - & 4 \\
\hline AML & - & - & 1 & 1 & - & - & 2 \\
\hline ITP & 1 & 1 & - & - & - & - & 2 \\
\hline MF & - & - & - & - & 1 & - & 1 \\
\hline ALL & 1 & - & - & - & - & - & 1 \\
\hline MDS & - & - & - & 1 & - & - & 1 \\
\hline Total & 11 & 21 & 29 & 11 & 4 & 1 & 77 \\
\hline
\end{tabular}

MA:Megaloblastic anemia; HIV: HIV associated dysplasia; Mixed anemia: Mixed nutritional deficiency anemia; AA: Aplastic anemia; AML: Acute myeloid leukemia; ITP: Idiopathic thrombocytopenic purpura; MF: Myelofibrosis; ALL: Acute lymphoblastic leukemia; MDS: Myelodysplastic syndrome

Table 2. Bone marrow aspiration findings in pancytopenia cases.

\begin{tabular}{|c|c|c|}
\hline \multicolumn{2}{|c|}{ Frequency } & Percentage (\%) \\
\hline \multicolumn{2}{|c|}{ Cellularity } \\
\hline Hypercellular & 64 & 83.1 \\
\hline Hypocellular & 3 & 3.9 \\
\hline Normocellular & 2 & 2.6 \\
\hline Diluted marrow/dry tap & 8 & 10.4 \\
\hline
\end{tabular}




\begin{tabular}{|c|c|c|}
\hline Features & Frequency & Percentage (\%) \\
\hline \multicolumn{3}{|c|}{ Erythroid series } \\
\hline Normoblastic maturation & 9 & 11.7 \\
\hline Megaloblastic maturation & 61 & 79.2 \\
\hline Dual maturation & 2 & 2.6 \\
\hline Cannot be commented & 5 & 6.5 \\
\hline \multicolumn{3}{|c|}{ Myeloid series } \\
\hline Normal maturation & 71 & 92.2 \\
\hline Blasts & 1 & 1.3 \\
\hline Cannot be commented & 5 & 6.5 \\
\hline \multicolumn{3}{|c|}{ Megakaryopoiesis } \\
\hline Normal & 68 & 88.3 \\
\hline Hypoplasia & 1 & 1.3 \\
\hline Hyperplasia & 3 & 3.9 \\
\hline Cannot be commented & 5 & 6.5 \\
\hline \multicolumn{3}{|c|}{ Iron stores } \\
\hline Low & 4 & 5.2 \\
\hline Normal & 66 & 85.7 \\
\hline High & 1 & 1.3 \\
\hline Cannot be commented & 6 & 7.8 \\
\hline
\end{tabular}

Table 3: Bone marrow biopsy findings in pancytopenia cases.

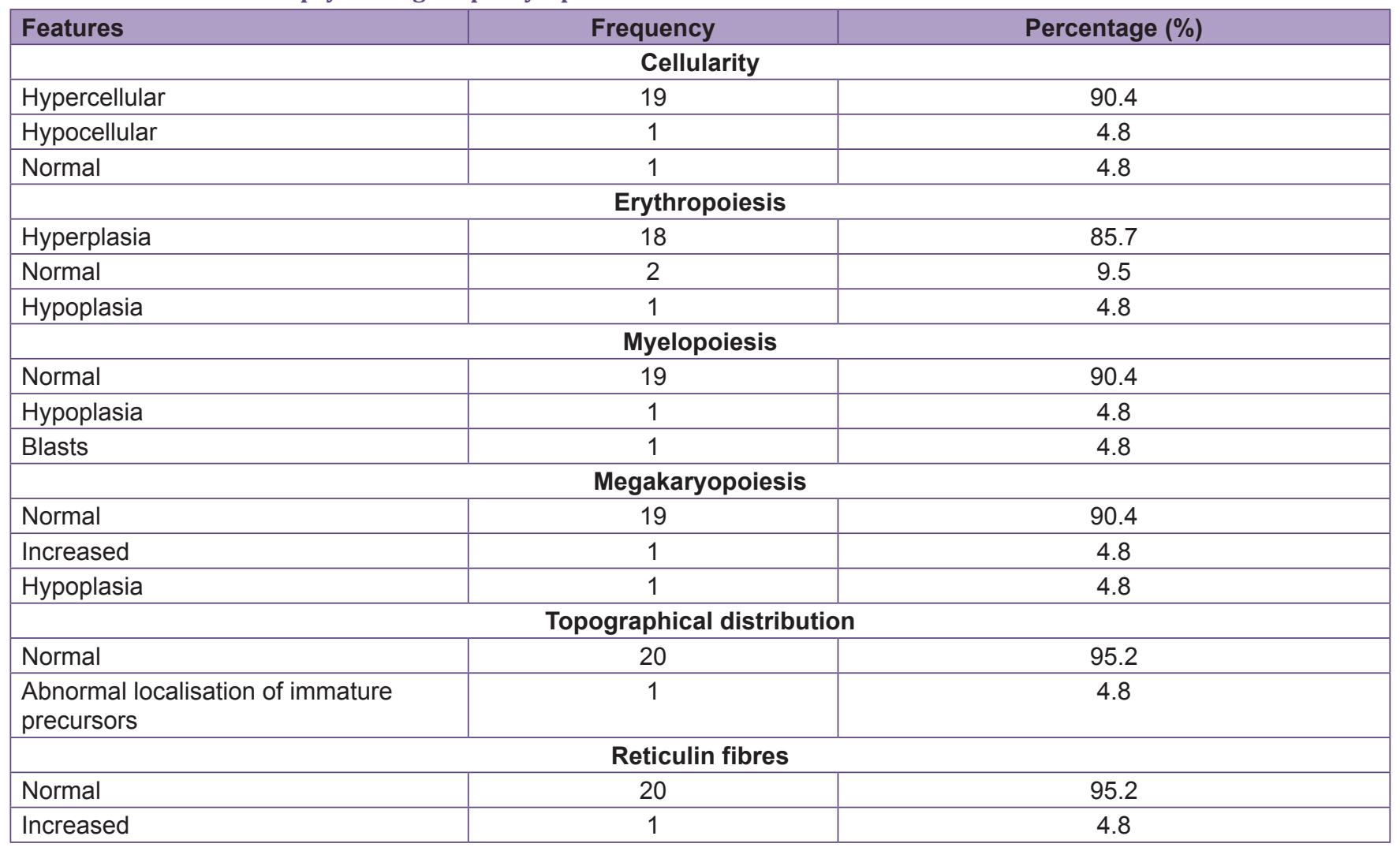


Table 4: Comparison of cause of pancytopenia with other authors' studies.

\begin{tabular}{|c|c|c|c|c|c|}
\hline Authors & $\begin{array}{l}\text { Number } \\
\text { of cases }\end{array}$ & $\begin{array}{l}\text { Study population } \\
\text { (Years) }\end{array}$ & $\begin{array}{l}\text { M:F } \\
\text { ratio }\end{array}$ & Most common cause & Second most common cause \\
\hline 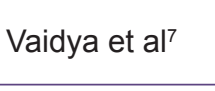 & 83 & $4-75$ & $1.3: 1$ & $\begin{array}{c}\text { Megaloblastic } \\
\text { anemia(34.95\%) }\end{array}$ & Aplastic anemia(31.33\%) \\
\hline Hamid et $\mathrm{al}^{8}$ & 75 & $3-85$ & 1.03:1 & Hypersplenism (28\%) & Malaria $(17.3 \%)$ \\
\hline Sale et $\mathrm{al}^{9}$ & 60 & $1-80$ & $0.9: 1$ & $\begin{array}{l}\text { Megaloblastic anemia } \\
\qquad(50 \%)\end{array}$ & Hypoplasia/ Aplasia(18.3\%) \\
\hline Dubey et $\mathrm{al}^{10}$ & 170 & $1-18$ & $0.88: 1$ & $\begin{array}{l}\text { Megaloblastic } \\
\text { anemia(47\%) }\end{array}$ & Aplastic anemia(25.8\%) \\
\hline Jan et $\mathrm{al}^{11}$ & 205 & $0.5-14$ & $1.8: 1$ & Aplastic anemia (28.3\%) & Hematological malignancies (23.9\%) \\
\hline Pereira et $\mathrm{al}^{30}$ & 80 & $4-80$ & 1.28:1 & $\begin{array}{l}\text { Megaloblastic } \\
\text { anemia(60\%) }\end{array}$ & $\begin{array}{c}\text { Aplastic anemia \&Subleukemic } \\
\text { leukemia (10\% each) }\end{array}$ \\
\hline Present study & 77 & $1.5-80$ & $1.7: 1$ & $\begin{array}{c}\text { Megaloblastic } \\
\text { anemia(64.9\%) }\end{array}$ & HIV associated dysplasia (15.6\%) \\
\hline
\end{tabular}

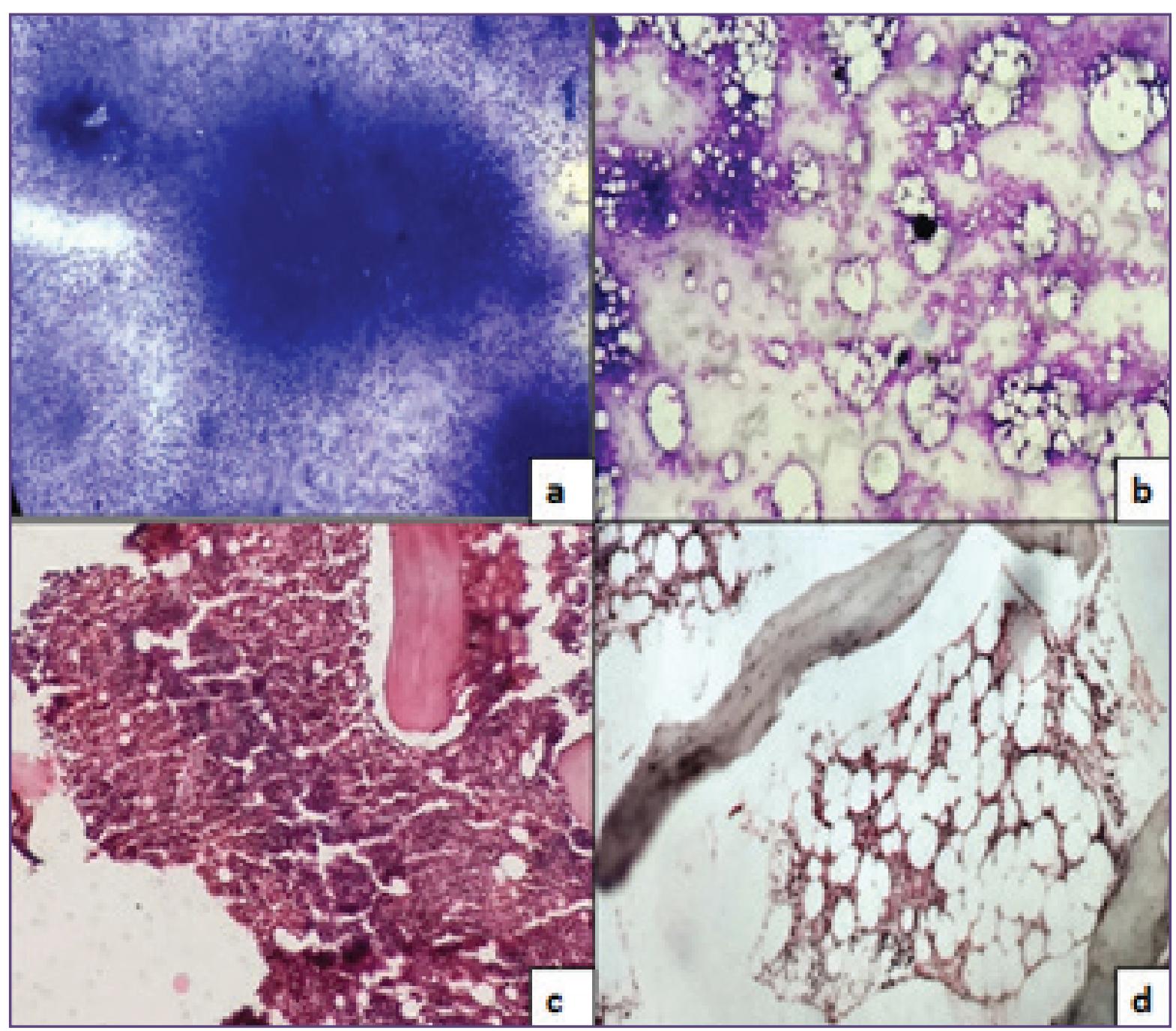

Fig. 1: BM aspiration a. Hypercellular marrow b. Hypocellular marrow. Lesihaman's stain (100x). BM biopsy c. Hypercellular marrow d. Hypocellular marrow. Hematoxylin\&Eosin stain(H\&E)(100x). 


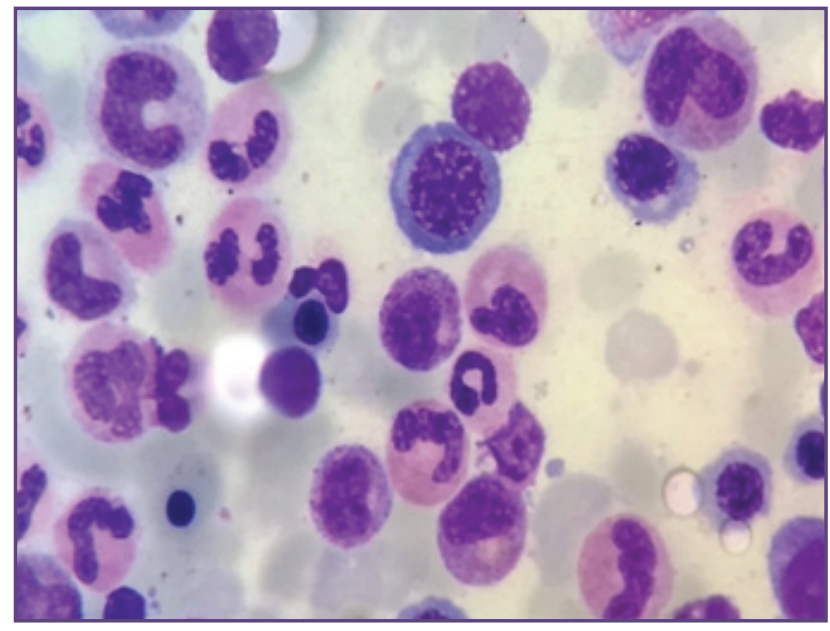

Fig. 2:BMA showing megaloblasts, giant metamyelocytes and giant band forms(arrows). Leishman's stain (1000x).

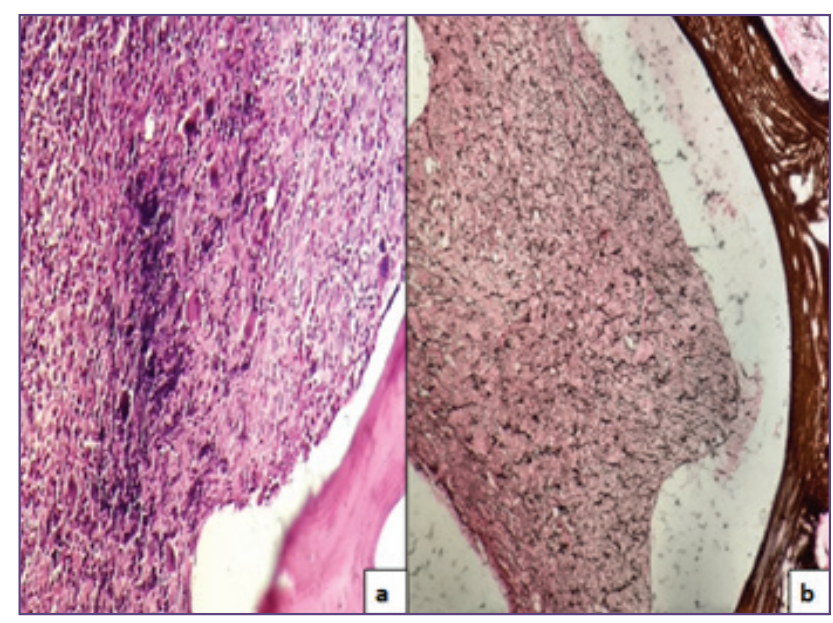

Fig. 4: Bone marrow biopsy of myelofibrosis a. Showing megakaryocytic hyperplasia(arrows) \& fibrosis. H\&E (100x) b. Grade 2 reticulin fibres. Reticulin stain (100x).

\section{Conclusion}

In our study, pancytopenia was a common clinical problem in adults as well as paediatric patients with nutritional deficiencies as the most common cause which were reversible and easily treatable. HIV associated dysplasia was another important cause of pancytopenia in our region indicating the association of pancytopenia with the socio demographic profile of patients. Other less common causes of pancytopenia were AA, acute leukemias, MDS, ITP and myelofibrosis and should always be considered in the differential diagnosis while investigating pancytopenia patient. The present study also concludes that detailed clinical examination and primary haematological investigations along with bone marrow aspiration and trephine biopsy were helpful for understanding the disease

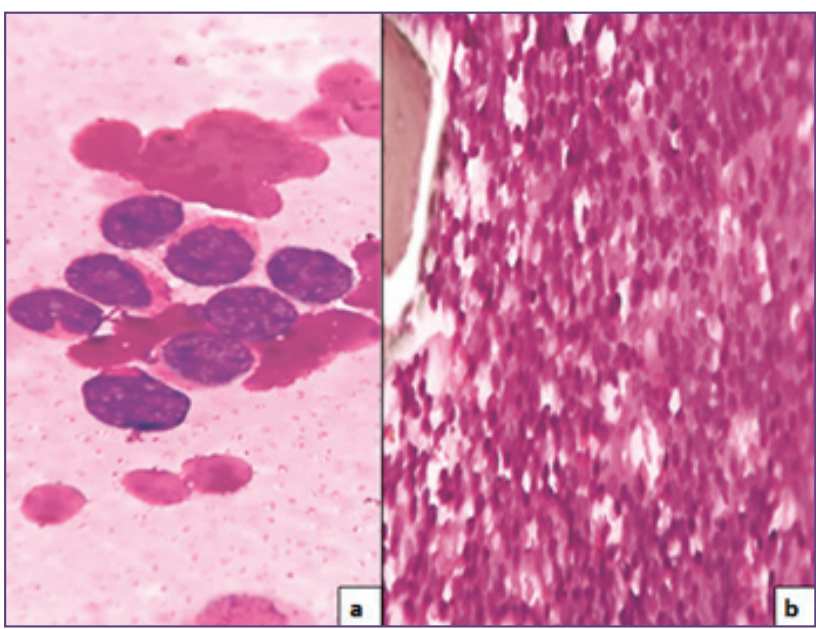

Fig. 3: Acute myeloid leukemia a. Bone marrow aspiration showing myeloblasts. Leishman's stain (1000x) b. Bone marrow biopsy section showing sheets of blasts. H \& E (400x).

process to diagnose and to plan further investigations and treatment in pancytopenia patients.

\section{References}

1. Gayathri BN, Rao KS. Pancytopenia - A Clinico Hematological Study. J Lab Physicians. 2011; 3(1):15-20.

2. Khunger JM, Arulselvi S, Sharma U, Ranga S, Talib VH. Pancytopenia - A clinic - hematological study of 200 cases. Indian J Pathol Microbiol. 2002; 45(3):375-79.

3. Khodke K, Marwah S, Buxi G, Yadav RB, Chatuvedi NK. Bone marrow examination in cases of pancytopenia. J Indian Acad Clin Med. 2001;2:55-9.

4. Thakkar BB, Bhavsar UN, Trivedi NJ, Agnihotri AS. A study of Pncytopenia in adult patients more than 12 years of age in North West region of Saurashtra. Nat J Med Research. 2013; 3(1): 48-52.

5. Metikurke SH, Rashmi K, Bhavika R. Correlation of bone marrow aspirate, biopsies and touch imprint findings in pancytopenia. J Hematol. 2013;2(1):8-13.

6. Patakh R, Jha A, Sayami G. Evaluation of bone marrow in patients with pancytopenia. J Pathol Nepal. 2012; 2:265-71.

7. Gupta M, Chandna A, Kumar S, Kataria SP, Hasija S, Singh G, Sen R. Clinicohematological profile of pancytopenia: A study from a tertiary care hospital. Dicle Med J. 2016; 43(1): 5-11.

8. Vaidya S. Evaluation of bone marrow in cases of pancytopenia in a tertiary care hospital. J Pathol Nepal. 2015; 5:691-5.

9. Hamid GA, Shukry SAR. Patterns of pancytopenia in Yemen. Turk J Hematol. 2008; 25:71-4.

10. Sale SM, Mane VP, Pawar VR, Mohite SN, Dhaka V. Clinical correlation of pancytopenia with bone marrow study in a tertiary hospital. Indian J Pathol Oncol. 2016; 3(2): 247-54.

11. Dubey SRK, Patel SK, Arya AK, Singh RP. Clinicoetiological spectrum of pancytopenia in hospitalised 
children. Internatl J Contemporary Pediatr. 2016; 3(1): 169172 .

12. Jan AZ, Zahid B, Ahmad S, Gul Z. Pancytopenia in children: A 6-year spectrum of patients admitted to pediatric department of Rehman Medical Institute, Peshawar. Pak J Med Sci. 2013; 29(5):1153-7.

13. Nigam RK, Chaudhary R, Malik R, Gour D, Shrivastava A, Tripathi A, Ahirwar R, Jain R. Pancytopenia- Clinicohematological studies of bone marrow examination. J Evolution Medl Dentl Sci. 2013; 2(47): 9213-9.

14. Tilak V, Jain Raini. Pancytopenia - A clinico-hematologic analysis of 77 cases. Indian J Pathol Microbiol. 1999; 42(4): 399-404.

15. Kumar DB, Raghupathi AR. Clinicohematological analysis of pancytopenia: Study in a tertiary care centre. Basic and Applied Pathol. 2012;5:19-21.

16. Naizi M, Raziq F. The incidence of underlying pathology in pancytopenia: an experience of 89 cases. J Postgrad Med Inst. 2014; 18:76-9.

17. Naseem S, Varma N, Das R, Ahluwalia J, Sachdeva MU, Marawaha RK. Pediatric patients with bicytopenia/ pancytopenia:review of etilogies and clinico-hematological profile at a tertiary centre. Indian J Pathol Microbiol 2011; 54: $75-80$.

18. Jha A, Sayami G, Adhikari RC, Panta AD, Jha R. Bone marrow examination in cases of pancytopenia. J Nepal Med Assoc. 2008; 47(169): 12-7.

19. Premkumar M, Gupta N, Singh T, Velpandian T. Cobalamin and folic acid status in relation to the etiopathogenesis of pancytopenia in adults at a tertiary care centre in North India. Anemia.2012; 2012:1-12.

20. Santiago-Rodriguez EJ, Mayor AM, Fernandez-Santos DM, Hunter-Mellado RF. Profile of HIV-Infected Hispanics with pancytopenia. Internatl J Enivironmental Research And Public Health. 2016;13:1-7.

21. Opie J. Hematological complications of HIV infection. South African Med J. 2012; 102(6): 465-8.

22. Gandhi PB, Shankar T, Pasha MA, Gouri M. Etiological and clinical spectrum of pancytopenia based on bone marrow examination and case records: A retrospective study. Annals of Applied Bio-Sci. 2016;3(1): 27-32.

23. Santra G, Das BK. A cross-sectional study of the clinical profile and aetiological spectrum of pancytopenia in a tertiary care centre. Singapore Medical J. 2010; 51(10): 80612.

24. Rathod GB, Alwani M, Patel H, Jain A. Clinicohematological analysis of pancytopenia in pediatric patients of tertiary care hospital. Internatl Archives of Integrated Med. 2015; 2(11): 15-19.

25. Khan FS, Hasan RF. Bone marrow examination of pancytopenic children. J Pak Med Assoc. 2012; 62(7): 6603.

26. Memon S, Shaikh S, Nizamani AA. Etiological spectrum of pancytopenia based on bone marrow examination in children. J Coll Physicians Surgeons Pak. 2008; 18(3): 1637.

27. Rehmani TH, Arif M, Haider S, Arif S, Ahmad R, Saeed M. Spectrum of pancytopenia; A tertiary care experience. Professional Med J. 2016; 23(5): 620-6.

28. Pine M, Walter AW. Pancytopenia in hospitalised children. A five year review. J Pediatr Hematol Oncol. 2010; 32:192-4.

29. Al-Awadi NB, Al-Awad AS, Al-yasiri HH. Patterns of Pancytopenia according to the cause in Babylon. Med J Babylon.2009; 6(4): 434-40

30. Pereira ADS, Dias A. Hematological Analysis of pancytopenia: A prospective study. Internatl J Scientific Study. 2016;4(4): 71-8.

*Corresponding author:

Dr. Rashmi K. Patil, W/O Dr.Naren V Nimbal, HNo: 201, First stage, Rani Channamma Nagar, Belagavi District, Karnataka, India- 590006.

Phone: +91 9986949387

Email: indiraanubrolu@gmail.com

Financial or other Competing Interests: None. 